\title{
Antioxidant Properties of Polysaccharide Extract from Juice and Pomace of Psidium guajava (Pink Guava) and its Mitigating Effect in Early Stage of Atherogenesis
}

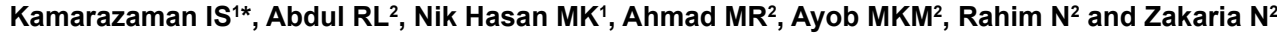

${ }^{1}$ Bioactivity Programme, Natural Products Division, Forest Research Institute of Malaysia (FRIM), 52109 Kepong, Selangor, Malaysia

${ }^{2}$ Phytochemistry Programme, Natural Products Division, Forest Research Institute of Malaysia (FRIM), 52109 Kepong, Selangor, Malaysia

\begin{abstract}
In this study, the polysaccharide extracts of Pink guava juice (PGJ) and pomace (PGP) were characterised and their antioxidant properties and mitigating effect on expression level of biomolecules involved in early stage of atherosclerosis were investigated. Chemical characterization were performed by HPLC and it was revealed that molar weight of PGJ and PGP by percentage (\%) were 63.0:16.2:9.9:6.4:4.2:0.1\% of galacturonic acid, xylose, glucose, mannose, galactose and rhamnose, respectively while PGP has 72.6:4.7:2.7:1.3\% of galacturonic acid, glucose, galactose and xylose, respectively. PGJ was found to has moderate antioxidant activity whereby PGP has more potent effect at lower concentration. Both PGJ and PGP have the ability to inhibit lipid peroxidation in dose dependent manner. Both also attenuate the tumor necrosis factor (TNF)- $\alpha$ induced ICAM-1 and VCAM-1 expression in dosedependent manner but only PGP could attenuate the MCP-1 expression.
\end{abstract}

Keywords: Atherosclerosis; Oxidative stress; Pink guava; Polysaccharide; Antioxidant; Lipid peroxidation

\section{Introduction}

Atherosclerosis is a chronic inflammatory disorder that can be recognised by the accumulation of cholesterol in arterial wall, hardening of the artery and formation of atherosclerotic plague [1]. Atherosclerosis is one of the most commonly occuring degenerative diseases [2]. It is well known that oxidation and inflammation play a key role in the initiation and the progression of atherosclerosis. Reactive oxygen species (ROS), which generated during oxygen metabolism in human body could turn LDL into as form that can easily taken up by macrophages (ox-LDL), then convert macrophages into foam cells [3,4]. Likewise, inflammation in vascular endothelial cells plays a crucial part in the progression of atherosclerosis. Inflammation induce cell injury and their activation which in turn upregulate the expression of intracellular cell adhesion molecule-1 (ICAM-1), vascular cell adhesion molecule-1 (VCAM1) and monocyte chemotactic protein 1 (MCP-1). Both ICAM-1 and VCAM-1 were implicated in the attraction and adherence of monocyte to vascular endothelium and their transendhothelial migration $[5,6]$ while MCP-1 plays a major role in the recruitment and infiltration of monocytes in injured endothelial cells [7].

Psidium guajava (Pink Guava) is a plant native to Mexico and other Central American countries including the Caribbean, Africa and Asia. Pink Guava has been traditionally used for the treatment of diabetes, hypertension, caries, wounds, pain relief and reducing fever. Several epidemiological studies have also found that Pink Guava has antioxidant, anti-inflammatory, antihyperglycemic and cardioprotective properties [8].

Polysaccharides are long carbohydrate molecule of repeated monomer units joined together by glycosidic bonds. The polysaccharide content in some food can be a major determinant to their anti-oxidant and anti-atherogenic properties. Several published studies have reported anti-atherogenic effect of polysaccharide fraction from plants. A study by Godard et al. [9] showed that polysaccharides from the green alga (Ulva rigida) improved antioxidant status and prevent fatty streak lesions in the high cholesterol fed hamster [9]. Previous study by Zha et al. [10] reported hypolipidemic activities of polysaccharide in Laminaria japonica diet-induced atherosclerotic mouse model. The anti-atherogenic property of polysaccharide also has been associated with its antioxidative properties as demonstrated by several scientists [11-13].

There were many studies have been performed on the polysaccharide extracts from various species of herbs and their role in the prevention on the onset of atherosclerosis. However, to the best of authors knowledge, no study on the effect of the polysaccharide extract from pink guava juice (PGJ) and pomace (PGP) on the prevention of atherosclerosis and any other cardiovascular associated diseases has been performed before. Therefore, present study was conducted with the aim to assess the monosaccharide composition of PGJ and PGP, to evaluate their antioxidant properties and their efficacy against lipid peroxidation and to determine their inhibitory properties against inflammatory process related to atherosclerosis.

\section{Materials and Methods}

\section{Sample collection}

Pink Guava fruits $(30 \mathrm{~kg}$ ) were collected from Golden Hope Food Beverages Sdn. Bhd., Sungai Wangi Plantation, Ayer Tawar, Sitiawan, Perak, Malaysia. Sample were authenticated by botanist from FRIM and the sample were deposited in FRIM Herbarium.

\section{Extraction of polysaccharide fraction from Pink Guava Juice} (PGJ)

Fresh fruits of pink guava were cut into slices and wrapped in cotton cloth prior to juice extraction. The juices were obtained by pressing the fruit slices using screw press equipment and the pomace were kept for

*Corresponding author: Insan Safwan Kamarazaman, Bioactivity Programme Natural Products Division, Forest Research Institute of Malaysia (FRIM), 52109 Kepong, Selangor, Malaysia, Tel: +60362797727; Fax: +60362729805; E-mail: insan@frim.gov.my

Received July 26, 2017; Accepted August 10, 2017; Published August 15, 2017

Citation: Kamarazaman IS, Abdul RL, Nik Hasan MK, Ahmad MR, Ayob MKM, et al. (2017) Antioxidant Properties of Polysaccharide Extract from Juice and Pomace of Psidium guajava (Pink Guava) and its Mitigating Effect in Early Stage of Atherogenesis. Nat Prod Chem Res 5: 270. doi: 10.4172/2329-6836.1000273

Copyright: () 2017 Kamarazaman IS, et al. This is an open-access article distributed under the terms of the Creative Commons Attribution License, which permits unrestricted use, distribution, and reproduction in any medium, provided the original author and source are credited. 
Citation: Kamarazaman IS, Abdul RL, Nik Hasan MK, Ahmad MR, Ayob MKM, et al. (2017) Antioxidant Properties of Polysaccharide Extract from Juice and Pomace of Psidium guajava (Pink Guava) and its Mitigating Effect in Early Stage of Atherogenesis. Nat Prod Chem Res 5: 273. doi: $10.4172 / 2329-6836.1000273$

Page 2 of 6

another experiment. Then 3 volumes of $95 \%$ ethanol were added to the juice extract until a formation of white precipitate occurred. The precipitate was separated from supernatant by centrifugation at $6300 \mathrm{~g}$ for $15 \mathrm{~min}$. The precipitate was then re-dissolved in distilled water and subsequently freeze-dried.

\section{Extraction of polysaccharide fraction from Pink Guava Pomace (PGP)}

The fruits pomace was dried at $50^{\circ} \mathrm{C}$ for a week. The dried pomace was grounded using homogeneous blender. Then secondary metabolites were removed from the grounded pomace by Soxhlet extraction and methanol was used as an extractant. The methanol extract was discarded and the pomace residues were collected and dried at room temperature.

The pomace residues were soaked in distilled water and boiled under reflux for $2 \mathrm{~h}$. After filtration, the aqueous extract was collected and evaporated under reduced pressure at $50^{\circ} \mathrm{C}$ to about $1 / 10$ of original volumes. Then 3 volumes of $95 \%$ ethanol were added to the concentrated extract until a formation of white precipitate occurred. The precipitate was separated from supernatant by centrifugation at $6300 \mathrm{~g}$ for $15 \mathrm{~min}$. The precipitate was re-dissolved in distilled water and freeze-dried.

\section{Characterization of monosaccharide composition in PGJ and PGP}

Both polysaccharides were hydrolyzed with $2 \mathrm{M}$ sulfuric acid at $120^{\circ} \mathrm{C}$ for $2 \mathrm{~h}$. The hydrolyzates was neutralized with sodium hydroxide and dried under reduced pressure. A monosaccharide compositions and carbohydrate contents of the polysaccharides were determined using the hydrolyzate. High performance liquid chromatography (HPLC) analysis was performed using Waters HPLC system, equipped with Waters 2707 auto sampler and Waters 996 Photodiode Array Detector (Waters, USA). A $5 \mu \mathrm{L}$ sample solution was injected onto a LiChroCART RP- $18 \mathrm{e}(250 \times 4.6 \mathrm{~mm}, 5 \mu \mathrm{m})$ column. A gradient elution was carried out using the following solvent systems: mobile phase A: Phosphate buffer, $\mathrm{pH} 7.0 \pm 0.2$ and mobile phase B- acetonitrile. The elution was performed with a gradient procedure as follows: $0-2 \mathrm{~min}$, $5 \% \mathrm{~B} ; 2-10 \mathrm{~min}, 10 \% \mathrm{~B} ; 10-15,14 \% ; 15-20,10 \%$ at a solvent flow rate $1.0 \mathrm{~mL} / \mathrm{min}$. Detection was performed at UV $254 \mathrm{~nm}$ for both PGJ and PGP. The working standards consisted a mixture of galacturonic acid (Gal. acid), galactose (Gal), glucose (Glu), arabinose (Ara), xylose (Xyl), mannose (Man) and rhamnose (Rham) for PGJ and PGP were also determined by HPLC, respectively [14].

\section{DPPH radical scavenging activity of PGJ and PGP}

Determination of antioxidant activity by DPPH radical scavenging method was carried out using a method described by Li and Shah [15] with some modification. One $\mathrm{mL}$ of the $0.45 \mathrm{mM} \mathrm{DPPH}$ (prepared in absolute ethanol) was added into $0.5 \mathrm{~mL}$ of each sample (500, 750 and $1000 \mu \mathrm{g} / \mathrm{mL}$ ). Butylated hydroxyl toluene (BHT) were used as positive control and absolute ethanol was used as negative control. All the samples were prepared in triplicates. The decrease of absorbance was monitored after $30 \mathrm{~min}$ incubation period at the wavelength 517 $\mathrm{nm}$ at room temperature. The antioxidant activity was expressed using following equation.

Scavenging effect $(\%)=\left[\mathrm{OD}_{\text {control }}-\mathrm{OD}_{\text {sample }}\right] / \mathrm{OD}_{\text {control }} \times 100 \%$

\section{Analysis of Total Phenolic Content (TPC)}

The determination of TPC was carried out using Folin-Ciocalteu method as described by Velioglu et al. [16]. Briefly, $200 \mu \mathrm{L}$ of the extract with concentration of $0.2 \mathrm{mg} / \mathrm{mL}$ was dissolved in $0.75 \mathrm{~mL}$ of $6 \%$ sodium carbonate $\left(\mathrm{Na}_{2} \mathrm{CO}_{3}\right)$ solution. The final mixture was shaken and then incubated for $90 \mathrm{~min}$ in a dark room at room temperature. The absorbance of all samples was measured at $725 \mathrm{~nm}$ using UVVis spectrophotometer. Gallic acid was used as a reference. Standard calibration curve was plotted at $0.02,0.04,0.06,0.08$, and $0.10 \mathrm{mg} / \mathrm{mL}$ gallic acid. The absorbance was recorded at $725 \mathrm{~nm}$. Total phenolic content was expressed as milligram of gallic acid equivalents (GAE) per 100 grams of samples.

\section{Anti-lipid peroxidation assay}

The effect of PGJ and PGP on $\mathrm{FeCl}_{3}$-egg yolk induced lipid peroxidation was determined as previously described [17]. In brief, a reaction mixture consisted of $0.5 \mathrm{~mL}$ of egg yolk homogenate (egg yolk: water=1:10), $0.05 \mathrm{~mL}$ of $4 \mathrm{mM} \mathrm{FeCl}_{3}$, and $0.1 \mathrm{~mL}$ of various concentrations of PGJ or PGP $(250,500$ and $750 \mu \mathrm{g} / \mathrm{mL})$ were incubated at $37^{\circ} \mathrm{C}$ for $1 \mathrm{~h}$, followed by a centrifugation $(3000 \mathrm{~g})$ for 10 min. A $0.1-\mathrm{mL}$ aliquot of the resulting mixture was mixed with $0.9 \mathrm{~mL}$ of distilled water and $1.0 \mathrm{~mL}$ of TBARS reagent (15\% TCA, $0.375 \%$ TBA in $0.25 \mathrm{~N} \mathrm{HCl}$ ) and then heated in a boiling water bath at $100^{\circ} \mathrm{C}$ for 30 min. After cooling, $3 \mathrm{~mL}$ of $\mathrm{n}$-butanol was added and the mixture was shaken vigorously. The n-butanol layer was separated by centrifugation (1200 g, $10 \mathrm{~min}$ ), and subjected to the measurement of TBA-reactive substances (TBARS) production at $532 \mathrm{~nm}$.

\section{Cell maintenance}

Human umbilical vein endothelial cells (HUVECs) were purchased from ScienCell (San Diego, CA, USA) and were cultured in endothelial cell medium (ECM) (ScienCell, San Diego, CA, USA) supplemented with $5 \%$ foetal bovine serum, $1 \%$ endothelial cell growth supplement (ECGS) (ScienCell, San Diego, CA, USA) and 1\% penicillin/streptomycin. HUVECs were cultured in $0.2 \%$ gelatin-coated tissue culture flasks in a humidified atmosphere containing $5 \% \mathrm{CO}$ incubator at $37^{\circ} \mathrm{C}$. Cells between third and fifth passages were grown to confluences before treatment with PGJ and PGP.

\section{In vitro cytotoxicity assay}

The cytotoxicity of each extract was evaluated by MTT assay as described by Tham et al. [18] with slight modification. Briefly, growing HUVECs were harvested and seeded in 96-well microplate at the density of $1 \times 10^{4}$ cells/well. Cells were allowed to attach and spread overnight prior to their incubation with the extracts at various concentrations $(0-1000 \mu \mathrm{g} / \mathrm{mL})$. After $24 \mathrm{~h}$ of incubation with the extract, MTT assay was carried out to determine the number of viable cells relative to the control cells. Each experiment was conducted in triplicate with three independent experiments. $\mathrm{IC}_{50}(50 \%)$ inhibition concentration values were determined from the corresponding dose response curve.

\section{Adhesion molecules and chemokine assay}

HUVECs were seeded at $1 \times 10^{5}$ on 6-well plate pre-coated with $0.2 \%$ gelatin. Cells were allowed to grow overnight before it were pretreated with 250,500 and $1000 \mu \mathrm{g} / \mathrm{mL}$ of PGJ and PGP, respectively. After $30 \mathrm{~min}$ of pretreatment of PGJ and PGP, TNF- $\alpha(10 \mathrm{ng} / \mathrm{mL}$ final concentration) was added to all well except for NC group and HUVECs were further incubated for $24 \mathrm{~h}$. After $24 \mathrm{~h}$ incubation periods, the cells supernatant were collected by centrifugation at $300 \mathrm{~g}$ for $5 \mathrm{~min}$. The cells supernatant were stored at $-20^{\circ} \mathrm{C}$ for further analysis of ICAM-1, VCAM-1 and MCP-1 level. ICAM-1, VCAM-1 and MCP-1 assay were performed by using commercially available kit (eBioscience, San Diego, CA, USA) and monitored using enzyme-link immunosorbent assay (ELISA) colorimetric approach. 
Citation: Kamarazaman IS, Abdul RL, Nik Hasan MK, Ahmad MR, Ayob MKM, et al. (2017) Antioxidant Properties of Polysaccharide Extract from Juice and Pomace of Psidium guajava (Pink Guava) and its Mitigating Effect in Early Stage of Atherogenesis. Nat Prod Chem Res 5: 273. doi: $10.4172 / 2329-6836.1000273$

Page 3 of 6

Table 1: Weight of dried polysaccharide, polysaccharide weight percent, total carbohydrate and total polysaccharide content of different parts of $P$. guajava.

\begin{tabular}{|c|c|c|c|c|c|c|}
\hline Sample & $\begin{array}{l}\text { Weight of dried } \\
\text { samples (kg) }\end{array}$ & $\begin{array}{c}\text { Weight of dried } \\
\text { polysaccharide }(\mathrm{g})\end{array}$ & $\begin{array}{c}\text { Polysaccharide } \\
\text { weight percent (\%) }\end{array}$ & \begin{tabular}{c|} 
Weight of dried \\
polysaccharides $(\mathrm{mg})$
\end{tabular} & $\begin{array}{l}\text { Weight of soluble } \\
\text { hydrolyzates }(\mathrm{mg})\end{array}$ & $\begin{array}{l}\text { Total carbohydrate } \\
\text { content }(\%)\end{array}$ \\
\hline PGJ & $4 \mathrm{~L}$ & 53 & & 300 & 100 & 100 \\
\hline PGP & 0.3 & 35.74 & 11.91 & 200 & 86 & 86 \\
\hline
\end{tabular}
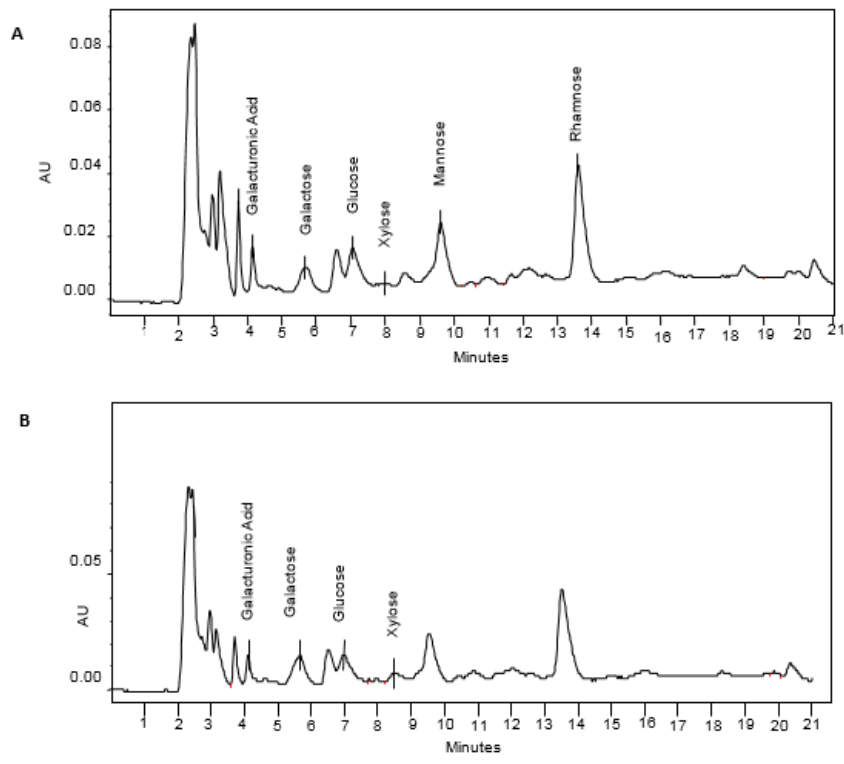

Figure 1: HPLC chromatogram of monosaccharide composition of polysaccharide fractions from pink guava: (A) PGJ : (B) PGP. PGJ, Pink Guava Juice polisaccharide extract; PGP, Pink Guava Pomace polisaccharide extract; $\mathrm{AU}$, absorbance unit. Mannose and rhamnose peak shown in Figure 1(B) were spiked with mannose and rhamnose standards, respectively.

A

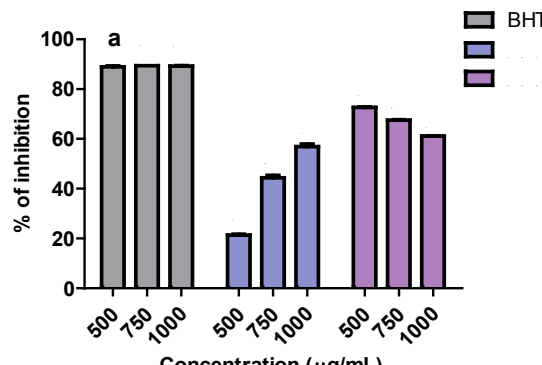

B

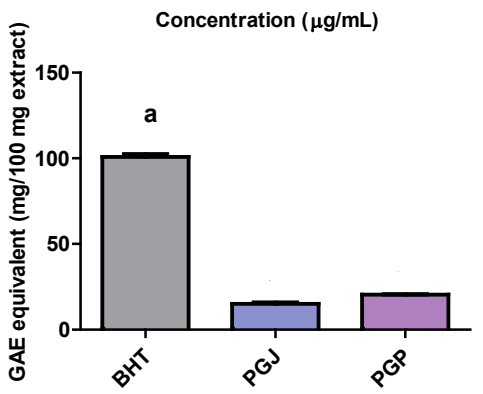

Figure 2: Antioxidant properties of PGJ and PGP: A) DPPH radical scavenging activity of PGJ and PGP. Data were expressed as mean of DPPH inhibtion (\%) \pm sd. B) Total phenolic content of PGJ and PGP. Data were expressed as mean of gallic acid equivalent per $100 \mathrm{mg}$ extract \pm sd. Values with different letter between same group of samples were significantly different $(p<0.01)$. PGJ, Pink Guava Juice polisaccharide extract; PGP, Pink Guava Pomace polisaccharide extract; $\mathrm{BHT}$, butylated hydroxyl toluene.

\section{Statistical analysis}

Statistical analysis for DPPH and TPC was performed by one-way
ANOVA with Turkey's posthoc multiple group comparison. Statistical analysis for MDA, ICAM-1, VCAM-1 and MCP-1 was performed by one-way ANOVA with Dunnet's posthoc multiple comparison test. The statistical analysis were performed using GraphPad Prism software (Version 5). $P<0.01$ was considered significant for all tests.

\section{Results and Discussion}

\section{Polysaccharides extraction and characterization}

The extraction yield of carbohydrate from PGJ and PGP were presented in Table 1. From $300 \mathrm{~g}$ weight of fresh sample, $35.74 \mathrm{~g}$ weight of dried polysaccharide obtained. Therefore, the percentage of PGP polysaccharide was $11.91 \%(w / w)$. For juice extract, $4 \mathrm{~L}$ of pink guava fresh juice resulted in $53 \mathrm{~g}$ yield of lyophilized polysaccharide. Total carbohydrate content from dried polysaccharide of juice and pomace extracts were 100 and $86 \%$, respectively.

The HPLC chromatogram of PGJ and PGP were depicted in Figure 1. From the HPLC chromatogram, it showed that polysaccharide fraction from juice extract contains galacturonic acid (GalA), xylose (Xyl), glucose $(\mathrm{Glc})$, mannose (Man), galactose $(\mathrm{Gal})$ and rhamnose (Rha) with weight percent (wt\%) 63.0: 16.2: 9.9: 6.4: 4.2: 0.1 while polysaccharide fraction from pomace extract contains methyl GalA, Glc, Gal and Xyl with weight percent (wt\%) 72.6: 4.7: 2.7: 1.3. The result revealed that there is some differences on the monosaccharide content between PGJ and PGP. PGP showed higher GalA content compared to PGJ while other monosaccharide such as xylose, glucose and galactose were detected at different level on both fractions. GalA is a main constituents of pectin [19]. The high content of GalA indicate high pectin content on both PGJ and PGP. Pectin, a high molecular weight heteropolysaccharide that contribute to the firmness and structure of the vegetal tissue is widely used as food ingridient and interfacial activity [20]. Beside it's used as food ingredient, pectin was also reported to contribute for various types of health benefit. A study by Brouns et al. [21] showed that apple and citrus pectin have cholesterol lowering properties on mildly hyper-cholesterolemic man and woman with both types of pectin give different degree of cholesterol lowering effect.

\section{Antioxidant properties of PGJ and PGP}

One of the most common method to evaluate antioxidant properties of plant extract is by measuring its DPPH scavenging activity. Plant extract with good antioxidant properties will have the ability to donate hydrogen/electron to the DPPH radicals and limit its damaging effect. DPPH scavenging effect of PGJ and PGP were demonstrated in Figure 2. From the figure, DPPH scavenging effect of PGJ was increased in dose dependent manner. DPPH scavenging efect of PGJ at 500, 750 and $1000 \mu \mathrm{g} / \mathrm{mL}$ were $21.35,44.39$ and $56.91 \%$, respectively while DPPH scavenging effect of PGP at 500, 750 and $1000 \mu \mathrm{g} / \mathrm{mL}$ were $72.63,67.50$ and $61.14 \%$, respectively. Both PGJ and PGP showed good antioxidant properties, albeit not as good as vitamin C. PGP showed higher DPPH scavenging activity with $72.63 \%$ of inhibition at $250 \mu \mathrm{g} / \mathrm{mL}$ while DPPH scavenging activity of PGJ at $1000 \mu \mathrm{g} / \mathrm{mL}$ was $56.91 \%$.

Total phenolic content of PGJ and PGP were $15.12 \pm 0.74$ and 20.44 $\pm 0.07 \mathrm{mg} \mathrm{GAE} / 100 \mathrm{mg}$ extract, respectively. Antioxidant properties of plant extracts were attributed to many groups of phytochemicals like polyphenols and flavonoids. Polyphenols, especially phenolic 
Citation: Kamarazaman IS, Abdul RL, Nik Hasan MK, Ahmad MR, Ayob MKM, et al. (2017) Antioxidant Properties of Polysaccharide Extract from Juice and Pomace of Psidium guajava (Pink Guava) and its Mitigating Effect in Early Stage of Atherogenesis. Nat Prod Chem Res 5: 273. doi: $10.4172 / 2329-6836.1000273$

compounds can be ubiquitously found in plants and serve as major source of antioxidants. High phenolic content in plant were closely related to increased antioxidant status and have been conformed by several studies [22-24]. Phenolic compounds were also reported attribute for wide range of biological activities including antiinflammatory, antimicrobial, chemopreventive and anticancer properties [25]. In this study, phenolic content was measured using gallic acid as a standard. The result showed that PGP possesses higher TPC value compared to that of PGJ. Eventhough TPC value of PGJ and PGP were not comparable than that of BHT, both PGJ and PGP showed considerabley high TPC value.

\section{Anti-lipid peroxidation activity of PGJ and PGP}

The result of anti-lipid peroxidation activity of PGJ and PGP were demonstrated in Figure 3. From the result, MDA value of egg yolk induced with $\mathrm{FeCl}_{3}$ was markedly increased compared to those of untreated egg yolk. Egg yolk that was pretreated with various concentration of PGJ and PJP have showed the mitigating effect on $\mathrm{FeCl}_{3}$-induced lipid peroxidation. PGJ at 250, 500 and $1000 \mu \mathrm{g} / \mathrm{mL}$ have significantly inhibited $\mathrm{FeCl}_{3}$-induced lipid peroxidation by 11.97, 31.23 and $38.46 \%$, respectively while PGP at 250,500 and $1000 \mu \mathrm{g} / \mathrm{mL}$ have significantly inhibited $\mathrm{FeCl}_{3}$-induced lipid peroxidation by 23.98, 44.76 and $54.04 \%$ of inhibition, respectively. Lipid peroxidation was postulated to be involved in early stage of atherosclerosis alongside the endothelial cell injury, activation of inflammatory cells and migration of smooth muscle cells into intima [9]. Many bioactive constituents from natural sources were tested for their ability to inhibit lipid peroxidation induced

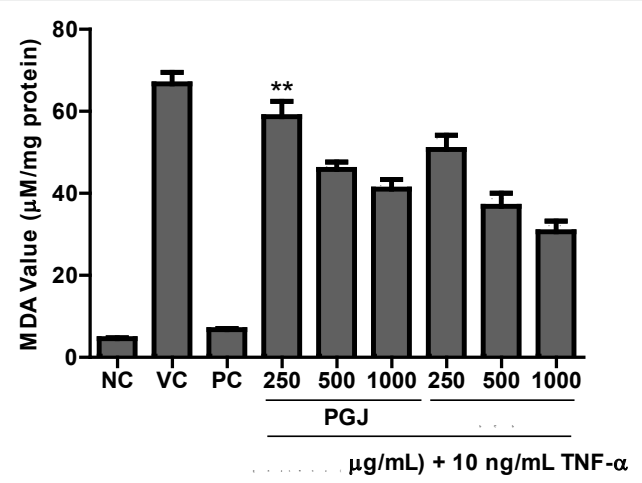

"Significantly difference compared to VC at $p<0.01$

Figure 3: MDA value of PGJ and PGP. Data were expressed as mean of MDA value per mg protein \pm sd. NC, Normal control; VC, vehicle control; PC, positive control; PGJ, Pink Guava Juice polisaccharide extract; PGP, Pink Guava Pomace polisaccharide extract.

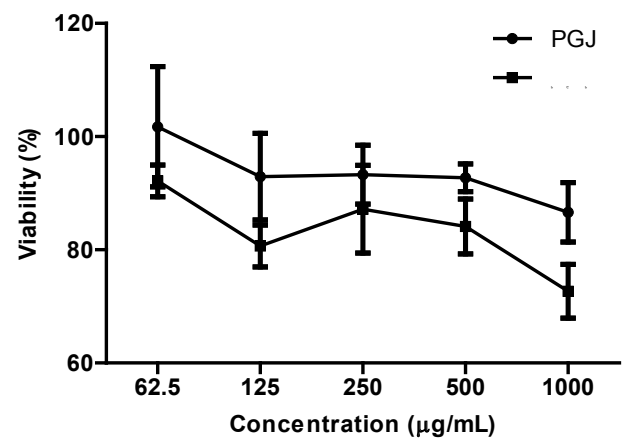

Figure 4: Viability of HUVECs against PGJ and PGP tested at $62.5-1000 \mu \mathrm{g} /$ $\mathrm{mL}$. Data were expressed as mean of viability (\%) \pm sd. PGJ, Pink Guava Juice polisaccharide extract; PGP, Pink Guava Pomace polisaccharide extract.
A

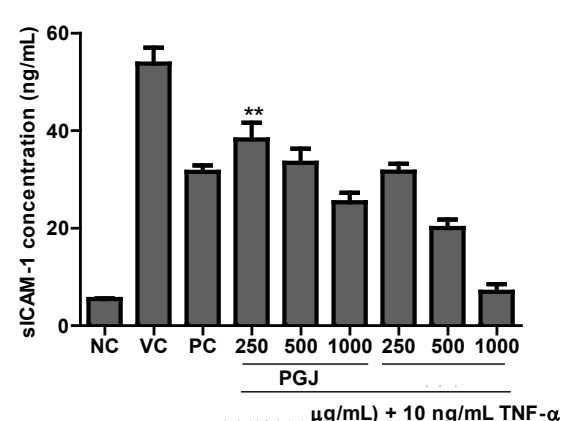

B

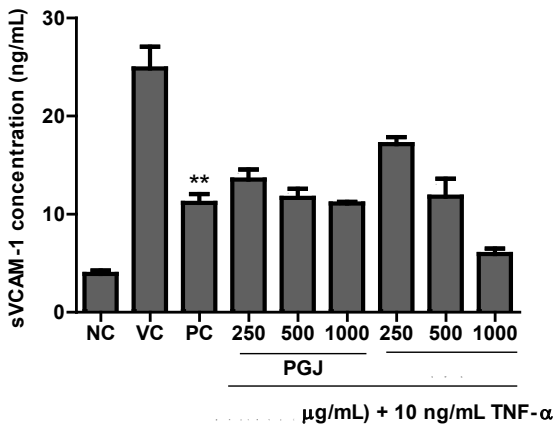

C

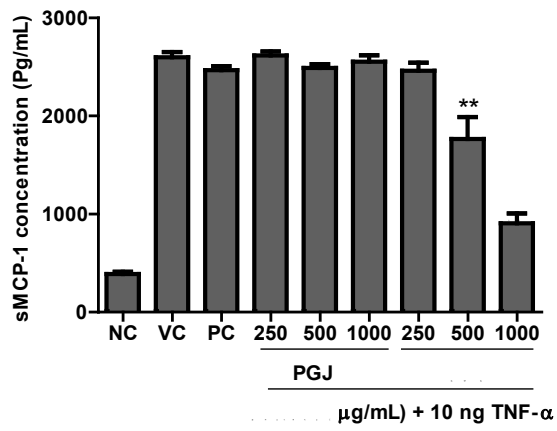

*Significantly difference compared to VC at $p<0.01$

Figure 5: Effect of Pink Guava Extracts on A) ICAM-1, B) VCAM-1 and C) MCP-1 inhibition on TNF-a induced HUVECs. NC, Normal control; VC, vehicle control; PC, positive control; PGJ, Pink Guava Juice polisaccharide extract; PGP, Pink Guava Pomace polisaccharide extract.

by various pro-oxidant and pro-inflammatory substances in vitro as potential candidate of anti-atherogenic agent [26]. Inhibition of lipid peroxidation by polysaccharide fractions has been reported on several occasions. A study by Hassan, El-Twab, Hetta and Mahmoud_[27] has reported that polysaccharide from green alga (Ulva lactuca Linnaeus) improved lipid profile and antioxidant of hypercholesterolemic albino rats. Recent study by Sun, Wang, Li and Liu [28] also demonstrated the lipid peroxidation induced by $\mathrm{Fe}^{2+}$ were inhibited by polysaccarides from $P$. viridis and S. Marina. Present study demonstrate the anti-lipid peroxidation properties of PGJ and PGP induced by $\mathrm{FeCl}_{3}$. Both PGJ and PGP could inhibit lipid peroxidation in dose dependent manner but PGP exhibit more potent effect. Inhibition of lipid peroxidation by PGJ and PGP suggest that they could be very useful in limiting the formation of oxidized LDL in circulatory vessels thus prevent cell injury and inflammatory cascades that lead to atherogenesis.

\section{Viability of HUVECs against PGJ and PGP}

Study on viability of HUVECs against PGJ and PGP (Figure 4) showed that both fraction were not toxic on HUVECs. The viability of HUVECs on the highest concentration used this study $(1000 \mu \mathrm{g} / \mathrm{mL})$ 
Citation: Kamarazaman IS, Abdul RL, Nik Hasan MK, Ahmad MR, Ayob MKM, et al. (2017) Antioxidant Properties of Polysaccharide Extract from Juice and Pomace of Psidium guajava (Pink Guava) and its Mitigating Effect in Early Stage of Atherogenesis. Nat Prod Chem Res 5: 273. doi: $10.4172 / 2329-6836.1000273$

Page 5 of 6

was only reduced to 86.63 and $72.68 \%$ when it is incubated for $24 \mathrm{~h}$ with PGJ and PGP, respectively.

\section{Effect of PGJ and PGP on ICAM-1, VCAM-1 and MCP-1 expression in TNF- $a$-induced HUVECs}

The effect of PGJ and PGP on ICAM-1, VCAM-1 and MCP-1 expression in TNF- $\alpha$-induced HUVECs were demonstrated in Figure 5. HUVECs were pretreated with $250,500,1000 \mu \mathrm{g} / \mathrm{mL}$ of PGJ or PGP before stimulated with $10 \mathrm{ng} / \mathrm{mL}$ of TNF- $\alpha$ for overexpression of ICAM-1, VCAM-1 and MCP-1. This has been confirmed by the result of this study as ICAM-1, VCAM-1 and MCP-1 expression were significantly increased in TNF- $\alpha$-induced HUVECs compared to that of untreated control.

Results from this study showed both PGJ and PGP have the ability to modulate the TNF- $\alpha$-induced expression of ICAM-1 and VCAM1 while only PGP at 500 and $1000 \mu \mathrm{g} / \mathrm{mL}$ modulate the expression of MCP-1. PGJ and PGP inhibition on ICAM-1 expression were in dose-dependent manner. PGJ at 250, 500, 1000, 1500 and $2000 \mu \mathrm{g} / \mathrm{mL}$ inhibit ICAM-1 expression by $28.90,37.88$ and $52.91 \%$ while PGP at indicated concentration inhibit ICAM-1 expression by 41.19, 62.66 and $87.02 \%$, respectively. Both PGJ and PGP also inhibit VCAM-1 in dosedependent manner. PGJ at 250, 500 and $1000 \mu \mathrm{g} / \mathrm{mL}$ inhibit VCAM1 expression by $45.49,53.14$ and $55.43 \%$, respectively while PGP at indicated concentration inhibit VCAM-1 expression by $31.09,52.53$ and $76.07 \%$, respectively. As for MCP-1 expression, only PGP could inhibit the MCP-1 expression on TNF- $\alpha$-induced HUVECs while PGJ showed no inhibition properties. PGP inhibit MCP-1 expression on TNF- a-induced HUVECs in dose-dependent manner with 5.34, 32.06 and $65.18 \%$ of inhibition at dose of 250,500 and $1000 \mu \mathrm{g} / \mathrm{mL}$, respectively.

Atherosclerosis is associated with many stress conditions including oxidative stress and inflammation in vascular endothelium, induced by many oxidants and inflammatory cytokines. Oxidative stress and inflammation caused cell injury, activate the endothelial cells to produce adhesion molecules, mainly ICAM-1 and VCAM- 1 and attract the monocyte to intima layer. Many published data has described that both ICAM-1 and VCAM-1 are predominantly expressed in the fatty streak of atherosclerotic lesion [29,30]. The upregulation of ICAM-1 and VCAM-1 was found to alter adhesive properties of the vasculature and lead to indiscriminate infiltration of monocytes across blood vessels [31]. Monocyte chemoattractant protein-1, on the other hand, mediate the sub endothelial migration of monocyte and their subsequent differentiation into macrophages. Upregulations of MCP-1 in HUVECs lead to increase permeability of endothelial cells towards monocyte which subsequently transformed into foam cell and accumulated as plaque. It is well established that upregulation of CAMs and MCP-1 expression can be induced by cytokines. In this study, ICAM-1 and VCAM-1 expression in HUVECs were upregulated after incubated with $10 \mathrm{ng} / \mathrm{mL}$ TNF- $\alpha$ for $24 \mathrm{~h}$. Both PGJ and PGP were able to attenuate the effect of TNF- $\alpha$ by suppressing the expression of ICAM-1, VCAM1 in dose dependent manner while only PGP were able to attenuate the expressions of MCP-1. The different modulating effect of PGJ and PGP on the upregulation of MCP-1 could be explained by a variability and different degree of monosaccharide composition of both extracts. PGP was found having considerably higher GalA content based on HPLC chromatogram described earlier. These variabilities could be the determining factor to the different inhibition properties of both extracts. The inhibition properties of both extracts on CAMs and MCP1 expressions showed their potential in mitigating the event that lead to the development of atheroma plaque in the vascular endothelium.

\section{Conclusion}

This study intends to shed light on the potential of pink guava juice and pomace polysaccharide fractions as antioxidant and anti-atherogenic agent and further be develop into supplement or functional food product. The monosaccharide compositions of PGJ and PGP were first elucidated and both fractions showed variation on its monosaccharide percentage. PGP contains more GalA while PGJ contains more Xyl and contains Rha and Man sugars. PGP showed stronger DPPH radical scavenging properties and possess more phenolics content compared to PGJ. Both fractions also showed remarkable effect in inhibiting lipid peroxidation induced by $\mathrm{FeCl}_{3}$ on lipid-rich egg yolk whereas PGP exhibited more evident effect. At the same time, PGJ and PGP could also inhibit the TNF- $\alpha$-induced expression of ICAM-1 and VCAM1. In agreement with lipid peroxidation inhibition, PGP exhibited stronger ICAM-1 and VCAM-1 inhibition properties compared to PGJ. Only PGP at 500 and $1000 \mu \mathrm{g} / \mathrm{mL}$ could inhibit TNF- $\alpha$-induced expression of MCP-1. Albeit the mechanisms of action were not fully understood, the remarkable inhibition properties of PGJ and PGP on lipid peroxidation, ICAM-1, VCAM-1 and MCP-1 demonstrate that they have a potential into developing a natural products-based supplement or functional food product.

\section{Acknowledgements}

This research was supported financially by FRIM's Grant for Research and Precommercialization (GPP-0912-SB-01)

\section{Conflict of Interest}

There is no conflict of interest.

\section{References}

1. Ross R (1999) Atherosclerosis-an inflammatory disease. The New England Journal of Medicine 340: 115-126.

2. Hansson GK, Hermansson A (2011) The immune system in atherosclerosis Nature Immunology 12: 204-212.

3. Henriksen T, Mahoney EM, Steinberg D (1983) Enhanced macrophage degradation of biologically modified low density lipoprotein. Arteriosclerosis 3 149-159.

4. Klinkner AM, Waites CR, Kerns WD, Bugelski PJ (1995) Evidence of foam cell and cholesterol crystal formation in macrophages incubated with oxidized LDL by fluorescence and electron microscopy. Journal of Histochemistry and Cytochemistry 43: 1071-1078.

5. liyama K, Hajra L, liyama M, Li H, DiChiara M, et al. (1999) Patterns of vascular cell adhesion molecule-1 and intercellular adhesion molecule-1 expression in rabbit and mouse atherosclerotic lesions and at sites predisposed to lesion formation. Circulation Research 85: 199-207.

6. Cybulsky MI, liyama K, Li H, Zhu S, Chen M, et al. (2001) A major role for VCAM1 , but not ICAM-1, in early atherosclerosis. Journal of Clinical Investigation 107 : 1255-1262.

7. Deshmane SL, Kremlev S, Amini S, Sawaya BE (2009) Monocyte chemoattractant protein-1 (MCP-1): An overview. Journal of Interferon and Cytokine Research 29: 313-326.

8. Gutierrez RMP, Mitchell S, Solis RV (2008) A review of its traditional uses phytochemistry and pharmacology. Journal of Ethnopharmacology 117: 1-27.

9. Godard M, Décordé K, Ventura E, Soteras G, Baccou JC, et al. (2009) Polysaccharides from the green alga Ulva rigida improve the antioxidant status and prevent fatty streak lesions in the high cholesterol fed hamster, an animal model of nutritionally-induced atherosclerosis. Food Chemistry 115: 176-180.

10. Zha XQ, Xiao JJ, Zhang HN, Wang JH, Pan LH, et al. (2012) Polysaccharides in Laminaria japonica (LP): Extraction, physicochemical properties and their hypolipidemic activities in diet-induced mouse model of atherosclerosis. Food Chemistry. 134: 244-252.

11. Wang Z, Luo D (2007) Antioxidant activities of different fractions of polysaccharide from Gynostemma pentaphyllum Makino. Carbohydrate Polymers 68: 54-58. 
Citation: Kamarazaman IS, Abdul RL, Nik Hasan MK, Ahmad MR, Ayob MKM, et al. (2017) Antioxidant Properties of Polysaccharide Extract from Juice and Pomace of Psidium guajava (Pink Guava) and its Mitigating Effect in Early Stage of Atherogenesis. Nat Prod Chem Res 5: 273. doi: $10.4172 / 2329-6836.1000273$

Page 6 of 6

12. Jiang YH, Jiang XL, Wang $P$, Hu XK (2005) In vitro antioxidant activities of water-soluble polysaccharides extracted from Isaria farinosa B05. Journal of Food Biochemistry 29: 323-335.

13. Ng TB, He JS, Niu SM, Zhao L, Pi ZF, et al. (2004) Gallic acid derivative and polysaccharides with antioxidative activity from rose (Rosa rugosa) flowers. Journal of Pharmacy and Pharmacology 56: 537-545.

14. Tang HL, Chen C, Wang SK, Sun GJ (2015) Biochemical analysis and hypoglycemic activity of a polysaccharide isolated from the fruit of Lycium barbarum L. International Journal of Biological Macromolecules 77: 235-242.

15. Li S, Shah NP (2013) Effect of various heat treatments on phenolic profiles and antioxidant activities of Pleurotus eryngii extracts. Journal of Food Science 78: 1122-1129.

16. Velioglu YS, Mazza G, Gao L, Oomah BD (1998) Antioxidant activity and total phenolics in selected fruits, vegetables, and grain products. Journal of Agricultural and Food Chemistry 46: 4113-4117.

17. Pandey N, Chaurasia JK, Tiwari AP, Tripathi, YB (2007) Antioxidant properties of different fractions of tubers from Pueraria tuberosa Linn. Food Chemistry 105: 219-222.

18. Tham CL, Liew CY, Lam KW, Mohamad AS, Kim MK, et al. (2010) A synthetic curcuminoid derivative inhibits nitric oxide and proinflammatory cytokine synthesis. European Journal of Pharmacology 628: 247-254.

19. Kohn R, Kovác P (1978) Dissociation constants of D-galacturonic and D-glucuronic acid and their O-methyl derivatives. Ctiem Zvesti 32: 478-485.

20. DeCindio B, Gabriele D, Lupi FR (2016) Pectin: Properties Determination and Uses. Encyclopedia of Food and Health 11: 294-300.

21. Brouns F, Theuwissen E, Adam A, Bell M, Berger A, et al. (2012) Cholesterollowering properties of different pectin types in mildly hyper-cholesterolemic men and women. European Journal of Clinical Nutrition 66: 591-599.

22. Sindi HA, Marshall LJ, Morgan MRA (2014) Comparative chemical and biochemical analysis of extracts of Hibiscus Sabdariffa. Food Chemistry 164 23-29.

23. Sumczynski D, Bubelova Z, Sneyd J, Erb-Weber S, Mlcek J (2015) Tota phenolics, flavonoids, antioxidant activity, crude fibre and digestibility in nontraditional wheat flakes and muesli. Food Chemistry 174: 319-325.

24. Zhang H, Shao Y, Bao J, Beta, T (2015) Phenolic compounds and antioxidant properties of breeding lines between the white and black rice. Food Chemistry 172: 630-639.

25. Halliwell B, Gutteridge JMC (2006) Free radicals in biology and medicine. Oxford: Clarendon Press.

26. Rice-Evans C, Leake D, Bruckdorfer KR, Diplock AT (1996) Practical approaches to low density lipoprotein oxidation: Whys, wherefores and pitfalls. Free Radical Research 25: 285-311.

27. Hassan S, El-Twab SA, Hetta M, Mahmoud B (2011) Improvement of lipid profile and antioxidant of hypercholesterolemic albino rats by polysaccharides extracted from the green alga Ulva lactuca Linnaeus. Saudi Journal of Biological Sciences 18: 333-340.

28. Sun L, Wang L, Li J, Liu H (2014) Characterization and antioxidant activities of degraded polysaccharides from two marine Chrysophyta. Food Chemistry 160: $1-7$.

29. DeGraba TJ, Siren AL, Penix L, McCarron RM, Hargraves R, et al. (1998) Increased endothelial expression of intercellular adhesion molecule-1 in symptomatic versus asymptomatic human carotid atherosclerotic plaque. Stroke 29: $1405-1410$

30. O'Brien KD, McDonald TO, Chait A, Allen MD, Alpers CE (1996) Neovascular expression of E-selectin, intercellular adhesion molecule-1, and vascular cell adhesion molecule-1 in human atherosclerosis and their relation to intimal leukocyte content. Circulation 93: 672-682.

31. Krieglstein CF, Granger DN (2001) Adhesion molecules and their role in vascular diseases. American Journal of Hypertension 14: 44S-54S. 